\title{
INCLUSÃO DE CRIANÇAS COM DEFICIÊNCIA NA ESCOLA REGULAR NUMA REgião do MUNicípio de SÃo Paulo: CONHECENDO ESTRATÉGIAS E AÇões
}

\author{
INCLUSION OF CHILDREN WITH DISABILITIES IN REGULAR SCHOOLS IN AN AREA \\ of SÃo PAULO: UNDERSTANDING STRATEGIES AND ACTIONS
}

\author{
Maria Emília Pires BRIANT ${ }^{1}$ \\ Fátima Corrêa OLIVER ${ }^{2}$
}

\begin{abstract}
RESUMO: a inclusão de alunos com necessidades educacionais especiais no ensino regular depende da preparação da comunidade escolar para promover a participação de todos os alunos. Foi objetivo deste estudo conhecer, do ponto de vista do professor do ensino fundamental da rede pública municipal, as estratégias pedagógicas que utilizavam para a inclusão de crianças com deficiência na classe comum. Para isso foram realizadas entrevistas semiestruturadas individuais e, posteriormente, grupais com 11 professores de cinco escolas, um representante do Centro de Formação e Acompanhamento à Inclusão e um coordenador pedagógico. As entrevistas foram gravadas e transcritas. Após diversas leituras foi possível identificar como temáticas principais: sentidos e imaginários do professor sobre a deficiência, formação do professor para efetivação do processo de inclusão, bem como a utilização de estratégias pedagógicas diferenciadas e formação de rede de apoio na escola. Os entrevistados utilizavam estratégias gerais como aula expositiva, debates, e específicas como: avaliação dos alunos, adaptação do material, atividades em duplas, parceria com o professor da sala de apoio e acompanhamento à inclusão. Parte dos entrevistados trouxe uma visão com relação aos alunos com deficiência permeada de possibilidades, acreditando no potencial de aprendizagem dos mesmos, enquanto para outros, o discurso centrou-se, sobretudo, na impossibilidade da aprendizagem. Os docentes identificaram a necessidade de apoio institucional para seu trabalho, incluindo possibilidades de formação a partir das demandas cotidianas. Responder às necessidades levantadas é parte dos desafios para implementar a Educação Inclusiva na perspectiva da Educação para Todos, para a efetivação dos direitos de crianças com necessidades educacionais especiais.
\end{abstract}

PALAVRAS-CHAVE: Educação Especial. Educação Inclusiva. Necessidades Educacionais Especiais. Crianças com Deficiência.

\begin{abstract}
Including students with special needs in regular education requires preparation by the school community in order to promotes participation of all students. The purpose of this study is to understand from the point of view of primary and secondary municipal public school teachers, the pedagogical strategies these teachers used to include children with special needs in regular classes. This required conducting semi-structured individual interviews and later semi-structured group interviews with 11 teachers of 5 schools, 1 representative of the Centro de Formação e Acompanhamento à Inclusão (Inclusion Training and Monitoring Center) and 1 Learning and Teaching Coordinator. The interviews were recorded and transcribed and after several readings it was possible to identify the key topics: the perceptions and mental images of the teacher on disability, the training of the teacher to promote actual inclusion, as well as the use of dedicated teaching strategies and the formation of a support network at school. The participants used general strategies such as lectures and debates, and specific strategies such as student assessments, adaptation of teaching materials, activities in pairs, and joint work with the assistant teacher and inclusion monitor. Part of the participants shared a positive idea about the special needs students, demonstrating they believed these students had potential for learning. The discourse of the other participants showed that they did not believe in these potentialities. The teachers identified the need for institutional support for their work, such as on-going teacher training based on daily demands. Part of the challenge of implementing an Inclusive Education program integrated to the Educação para Todos (Education for All) idea requires us to face demands such as these in order to effectively enforce the rights of children with special learning needs.
\end{abstract}

KEYWORDS: Inclusive Education. Special Education. Special Educational Needs. Children with Disability.

\footnotetext{
${ }^{1}$ Universidade de São Paulo, Departamento de Fisioterapia, Fonoaudiologia e Terapia Ocupacional da Faculdade de Medicina da Universidade de São Paulo. mamibriant@usp.br

${ }^{2}$ Universidade de São Paulo, Departamento de Fisioterapia, Fonoaudiologia e Terapia Ocupacional da Faculdade de Medicina da Universidade de São Paulo. fcoliver@usp.br
} 


\section{INTRODUÇÃo}

A participação de crianças com deficiência na escola é um direito (BRASIL, 1996), que para ser acessado depende, entre outros aspectos, da articulação entre profissionais, famílias e sociedade para o cumprimento de diretrizes educacionais, destinação de recursos humanos e materiais e formação de profissionais habilitados para o enfrentamento dos diferentes desafios trazidos pela prática cotidiana do ensino.

A necessidade de formação dos professores para educação inclusiva e a falta de preparo para assumir a responsabilidade de promover a aprendizagem e participação de alunos com necessidade educacionais especiais, já foi estudada por diversos autores como Martins (2006), Vitaliano (2007), Hummel (2007), Beyer (2003). Tais autores, constataram as dificuldades e falta de preparo dos professores para promover a aprendizagem de alunos com necessidades educacionais especiais e enfatizaram a necessidade da formação continuada para atender à diversidade das experiências e demandas dos estudantes em sala de aula. Na prática, encontramos ainda professores despreparados para essa realidade e com falta de uma rede de apoio para desenvolver o seu trabalho com qualidade.

Essa rede de apoio voltada para a construção de possibilidades de inclusão de crianças com deficiências na escola pode envolver além de diferentes profissionais do campo da educação, profissionais da área da saúde, como o terapeutas ocupacional, por meio do trabalho de apoio direto ou indireto ao professor, à família, à comunidade escolar e também à criança.

A composição de uma equipe multidisciplinar é fundamental para apoiar e construir novas possibilidades de ação por parte dos diferentes agentes e para a efetivação e fortalecimento de uma nova dinâmica que valorize cada sujeito e sua diversidade.

A fim de contribuir para a construção do trabalho multidisciplinar no campo da inclusão escolar de crianças com deficiências, este estudo procurou conhecer, do ponto de vista de professores de ensino fundamental de escolas públicas municipais, quais as estratégias pedagógicas que utilizam em seu trabalho docente.

As estratégias utilizadas pelos professores na escola e na sala de aula possibilitam o desenvolvimento do processo de inclusão escolar de crianças com deficiência levantando questões relacionadas ao envolvimento do docente com esse trabalho e à necessidade de equiparar oportunidades de acesso e aprendizagem para todos os alunos.

A utilização de estratégias pedagógicas diferenciadas pode ser pensada como um recurso, que possibilita o acesso de todos os alunos ao conhecimento e é descrita por Braccialli e Paiva e (2010); Manzini e Santos (2002); Almirall, SoroCamats e Bultó (2003); Manzini e Deliberato (2004) como elemento facilitador para efetivar com qualidade o processo de inclusão escolar de crianças com deficiência na escola regular. 
Para esses autores uma dessas estratégias relaciona-se à utilização de recursos adaptados a serem acionados de acordo com a necessidade de cada aluno. Esses recursos podem ser simples ou envolver tecnologias mais avançadas como programas específicos de computação.

De acordo com Bordenavee Pereira (2007), as estratégias estão relacionadas com a forma de oferecer ao aluno oportunidade para viver as experiências desejadas, são também as maneiras de estruturar a atividade, isto é, estabelecer situações de ensino-aprendizagem, em que haja uma alta probabilidade de que ditas experiências realmente aconteçam.

Autores como Solé (1999) e Carlini (2004) identificaram estratégias que chamaremos de gerais, que podem ser utilizadas por qualquer professor para atingir todos os alunos, tais como: planejamento da aula, apresentação de idéias, aula expositiva, debates, dramatização, pesquisas, projetos, estudo dirigido, estudo do meio, seminários, trabalhos em grupo e ainda atividades em dupla.

Outros autores como Stainback e Stainback (1999) trouxeram estratégias específicas, que poderiam ser usadas pelo professor com um aluno com deficiência, como era o caso da utilização de sistemas de comunicação alternativa, a colaboração entre os pares, a administração do tempo para o planejamento adequado das atividades e a prática do manejo do conteúdo.

Entendemos que, na perspectiva da educação inclusiva, uma classe heterogênea com crianças com e sem deficiências pode ser vista como um estímulo, que provoca a adoção de estratégias destinadas a criar um ambiente educativo mais rico para todos, ou seja, as mudanças metodológicas e organizativas passam a responder aos alunos que apresentam dificuldades, porém podem beneficiar todos os alunos da sala de aula.

A criação de um ambiente educativo rico também está relacionada ao espaço que é destinado à formação continuada dos professores no sentido de apoiar seu trabalho cotidiano em sala de aula.

No entanto, a heterogeneidade dos alunos também pode causar angústia no professor que, muitas vezes, sente-se inseguro e impotente para desenvolver seu trabalho. Nesse sentido Perrenoud e Thurler (2001) trouxeram contribuições quando afirmam que a dimensão dos limites do próprio professor diante de algumas situações em que se sente impotente ou angustiado influencia, diretamente, seu trabalho em sala de aula.

Quando conversamos com professores, é comum ouvir que se sentem angustiados, sobretudo, quando recebem um aluno que, supostamente, não consegue aprender, ou tem uma dificuldade de comportamento com a qual ele não consegue lidar. Autores como Leonardo (2008), Ferraz, Araujo e Carreiro (2010), trazem essa discussão apontando que os professores sentem-se desamparados e inseguros com relação ao trabalho com a diversidade. 
Anjos, Andrade e Pereira (2009), apontam também os sentimentos dos professores com relação a seu trabalho, destacando-se: o choque sentido por eles no início do trabalho com alunos com deficiência, que faz com que percebam um vazio na sua formação e a falta de treinamento e conhecimentos específicos, assim como o fato de que esses novos sujeitos na sala de aula, exigem novas capacidades e novos modos de pensar também do professor. Dessa maneira, além da formação continuada é fundamental que o professor conte com uma rede de apoio na escola para auxiliá-lo no desenvolvimento de seu trabalho, que pode ser composta pelo coordenador pedagógico ou ainda pela articulação de seu trabalho ao de uma Sala de Apoio e Acompanhamento à Inclusão (SAAI), como é o caso de algumas escolas municipais da cidade de São Paulo.

Essas salas possuem professor especialista no ensino de crianças com diferentes tipos de deficiência e que normalmente atende educacionalmente alunos com necessidades educacionais especiais em um horário contrário ao do ensino regular, iniciativa que é parte da política educacional de inclusão de crianças com deficiências no município.

Assim, merece ser destacada a necessidade de investimento em estudos que considerem as políticas, as ações, as dificuldades práticas encontradas pela comunidade escolar em seu trabalho cotidiano, para redimensionarmos ações que, efetivamente, facilitem o acesso e a permanência dos alunos com deficiência na escola regular.

Este estudo, a partir dos referenciais da Educação para Todos e seus desdobramentos para a educação inclusiva, teve como objetivo principal conhecer do ponto de vista e da percepção de professores do ensino fundamental, as estratégias que utilizam para favorecer a inclusão de crianças com deficiência na classe comum da escola regular.

\section{Método}

Para atingir o objetivo desta pesquisa optou-se pela realização de um estudo descritivo, a partir de elementos da pesquisa qualitativa, que, segundo Chizzotti (2003), possibilita que todos os participantes sejam reconhecidos como sujeitos, que elaboram conhecimentos e produzem práticas adequadas para intervir nos problemas que identificam.

\section{Participantes}

O estudo foi realizado no período de agosto de 2006 a junho de 2007. As escolas participantes da pesquisa foram definidas no contato direto com o Centro de Formação e Acompanhamento à Inclusão (Cefai) considerando aquelas com maior número de crianças com deficiência, e também que já possuíam disponibilidade 
para estabelecer uma parceria com esse centro, na tentativa de construir uma rede de apoio à inclusão de crianças com necessidades educacionais especiais na escola.

Essas escolas faziam parte da região oeste do município de São Paulo, região escolhida pelo fato de já ter uma abertura de trabalho na perspectiva da educação inclusiva e pela proximidade com a Universidade de São Paulo pensando em possíveis desdobramentos, como projetos de extensão universitária. O critério de inclusão de professores nesta pesquisa foi a experiência de, no mínimo, um ano, como responsável por classe comum que contava com participação de crianças com deficiência como forma de assegurar familiaridade com a temática a ser desenvolvida.

A pesquisa foi apresentada às 11 escolas da região indicadas pelo Cefai sendo que destas apenas 5 aceitaram participar. $O$ estudo também foi apresentado aos professores dessas escolas, que se disponibilizaram a partir do interesse pelo tema. Nestas escolas 11 professores se dispuseram a ser entrevistados individualmente e depois em grupo. Entre os professores entrevistados estavam 10 mulheres e 1 homem, sendo 10 professores da classe comum e 1 professor da Sala de Apoio e Acompanhamento à Inclusão.

Também foi entrevistado um representante do Cefai, para conhecer as estratégias de trabalho do órgão responsável pela formação docente na região e 1 coordenador pedagógico (CP), selecionado entre as escolas participantes pela disponibilidade em participar da pesquisa e familiaridade com o tema.

\subsection{Materiais e instrumento}

Utilizamos a entrevista semiestruturada como forma de coleta de dados de todos os entrevistados. De acordo com May :

[...] esse tipo de entrevista permite que as pessoas respondam mais nos seus próprios termos, do que as entrevistas padronizadas, mas ainda fornecem uma estrutura maior de compatibilidade do que nas entrevistas focalizadas (MAY, 2004, p.149)

As entrevistas tratavam de temas como a formação do professor, o cotidiano e as rotinas em sala de aula bem como as estratégias de ensino que utilizava para trabalhar com todos os alunos, assim como os apoios que recebia na escola para o desenvolvimento de sua atividade docente.

\subsection{ANÁlise DE DADOS}

$\mathrm{Na}$ primeira leitura para análise das entrevistas buscamos, primordialmente, identificar aspectos significativos no discurso dos professores, temas recorrentes, elementos com características comuns ou que se relacionavam entre si. Essa análise inicial levantou alguns temas, que consideramos 
fundamentais para compreender como e porque os professores criavam ou utilizavam estratégias pedagógicas com seus alunos. Esses temas auxiliam a compreensão do cotidiano de trabalho docente e de sua perspectiva sobre as possibilidades de desenvolvimento da participação dos alunos com necessidades especiais na escola, contexto concreto para o desenvolvimento das estratégias pedagógicas. Assim, os temas recorrentes nas entrevistas foram os sentidos e imaginários do professor sobre a deficiência, a formação do professor para educação inclusiva, a utilização de estratégias pedagógicas diferenciadas e a formação de rede na escola.

Em uma segunda leitura das entrevistas transcritas examinamos separadamente as entrevistas individuais e coletiva, a fim de perceber a existência de hierarquias entre os elementos que apareceram e fazer um diálogo de cada professor com a escola na qual trabalhava individualmente e, depois, com o conjunto de todos os professores. O mesmo procedimento foi utilizado para entrevistas com o coordenador pedagógico e com o integrante da equipe do Cefai.

Após uma nova escuta do áudio de todas as entrevistas reafirmamos como elementos comuns e que apareceram diversas vezes nos discursos de cada agente tanto os sentidos e imaginários do professor sobre a deficiência, como as dificuldades colocadas para a formação do professor, a utilização de estratégias pedagógicas diferenciadas e a necessidade de formação de rede na escola.

\section{Resultados E discussão}

Os resultados e a discussão são organizados e apresentados, segundo as temáticas anteriormente apontadas.

\subsection{SENTIDOS E IMAGINÁRIOS DO PROFESSOR SOBRE A DEFICIÊNCIA}

No recorte desta pesquisa, a percepção da diversidade, ou ainda, as atitudes dos professores que prevaleceram em relação aos alunos com deficiência foram aquelas relacionadas à necessidade de cumprimento legal da matrícula desses alunos e à sua aceitação forçada no ambiente escolar, pois os professores vêem poucas possibilidades de aprendizagem para esses alunos. Essas reflexões são importantes, pois a atitude e a posição que o professor ocupa frente à diversidade cultural, biológica, psicológica ou social de seus alunos tem papel decisivo em sua prática cotidiana.

Uma das professoras entrevistadas afirma:

Eu nem acho que dá para fazer uma adaptação curricular para ela (aluna), ela está muito abaixo do normal, não rabisca, não escreve nem o nome, o nível dela é muito baixo, só está nessa sala porque é inclusão mesmo (P 1, Entrevista 1) 
As percepções e atitudes dos professores não podem ser isoladas do contexto em que estão inseridos e que, muitas vezes, gera sofrimento e impotência, de forma que não só os alunos, como também seus professores vivenciam um processo de exclusão/inclusão.

Apesar disso, reconhecemos algumas atitudes de grupos de professores, coordenadores e diretores, que produziram ações que valorizam as diferenças, que percebem as dificuldades, mas não se paralisam diante destas. Essas construções relacionam-se com a formação de uma rede de apoio na escola, com um sentimento de pertencimento e comprometimento com as ações do grupo, como aponta uma das professoras entrevistadas:

Tento ao máximo fazer o trabalho em equipe, mas tem sempre aqueles com que a gente se identifica mais e que se identificam mais com o trabalho da inclusão, e é neles que eu busco me apoiar. Aqui na escola, a gente tem uma SAAI, e a professora é muito legal. Ela atende as crianças da minha sala, e agente troca muito. É uma ajuda e um reforço muito importante. (P 3, Entrevista 3)

\section{Outro entrevistado afirma:}

Também procuro bastante a Isabel (professora da SAAI). Ela ajuda muito a gente, às vezes vai na sala de aula. É muito bom ter esse recurso na escola (P4, Entrevista 4).

Contar com uma rede de apoio possibilita que o trabalho fique mais estruturado, o aluno com deficiência deixa de ser visto como um problema, e o professor sente-se mais livre para exercer sua criatividade e encontrar respostas positivas.

A partir dessa postura é possível enxergar além da deficiência e reconhecer naquele aluno um sujeito capaz de aprender, como aponta uma das professoras entrevistadas:

Eu acho que o principal é a aceitação. Se não tiver uma atitude positiva desde o começo do ano, se eu não me envolver (olhar, perceber, aceitar), eu não vou conseguir que ele se desenvolva. (P5, Entrevista 5)

Ou ainda:

Na verdade, eu não vejo eles como deficientes, para mim eles são normais. Eu não vejo pela questão da deficiência, mas pela questão de uma dificuldade, de procurar uma forma de chegar até eles. (P6, Entrevista 6)

A partir dessa aceitação é possível construir um olhar voltado para as possibilidades e traçar estratégias e ações, que facilitem a participação desse aluno em todas as atividades da escola. A aceitação e o reconhecimento de que esse aluno é um sujeito e que ele é capaz de aprender constituem a base para traçar estratrégias para equiparar oportunidades em sala de aula, assim como para assegurar o acesso ao direito à educação 


\subsection{A FORMAÇÃo do PROFESSOR PARA EdUCAÇÃo INCLUSIVA}

A Educação Inclusiva ainda faz parte de uma perspectiva nova, os professores trazem uma série de angústias e muitas vezes, sentem-se impotentes e incapazes de lidar com essa nova realidade.

Discutir a necessidade de formação do professor para realizar esse trabalho é sem dúvida importante, porém, não podemos deixar de olhar a formação geral do professor, que deve estar preparado para uma educação para a diversidade em sentido amplo, para uma sociedade multicultural, capaz de ouvir, prestar atenção ao diferente e respeitá-lo. Dessa forma, nesse cenário, é preciso reconstruir o saber da escola e a formação do professor. Nessa perspectiva, temos o desafio de formar professores que, a partir de diferentes conhecimentos adquiridos, possam interpretar a realidade de que fazem parte com uma postura crítica e construtiva.

A partir do discurso dos professores percebemos a carência de oportunidades de formação continuada e a necessidade de que tais formações tenham uma interlocução com a prática: "Tive oportunidade de fazer apenas um estágio, mas sinceramente não foi muito produtivo, pois estava muito longe da nossa realidade em sala de aula". (P7, Entrevista 7)

Ou ainda:

Só tive chance de fazer um curso informativo sobre Libras mas na prática não me ajudou, foi muito básico e não me ajudou na prática com um aluno que tive em sala (P 8, Entrevista 8)

Alguns professores apontaram que muitos cursos que realizaram em sua experiência docente não foram efetivos na prática em sala de aula, ao mesmo tempo, uma das entrevistadas aponta uma experiência de formação positiva justamente por considerar a demanda e a angústia do professor:

O grupo de educação especial da Coordenadoria dava palestras, cursos, levavam especialistas, tinha discussão de casos, levávamos o trabalho das crianças, filmávamos, discutíamos com especialistas e lá discutíamos caso por caso. Em 2004, nós tivemos uma assessoria toda última sexta-feira do mês e todos os professores da região, que tinham alunos de inclusão participavam. Nós discutíamos casos, todos colocavam sua opinião, o pessoal conhecia muitas crianças, os profissionais que trabalhavam com as crianças, tinham esse intercâmbio, tinha uma rede. (P 9, entrevista 9)

Ou ainda:

Participei de apenas um curso, a rede oferece poucos e nunca é para escola toda. Me ajudou porque eu troquei com outros colegas, tiveram vivências interessantes e não deram receita, me ajudaram a pensar em como agir em algumas situações. (P10, Entrevista 10)) 
Destacamos essas experiências, pois em sua maioria os professores declararam que os cursos que realizaram foram meramente informativos ou então muito técnicos, com poucas possibilidades de discutir as orientações a partir da prática em sala de aula.

A necessidade de formação continuada é uma realidade para todos os professores e não só para aqueles que trabalham com alunos com deficiência. A proposta de Educação para Todos traz uma discussão, que envolve a melhoria da qualidade de ensino para Todos os alunos. Dessa forma, é fundamental pensar nesse processo e considerar as questões supracitadas, no que se refere à interlocução teórico- prática para que efetivamente o professor seja protagonista na construção de uma nova prática.

É preciso investir no processo de formação inicial e continuada do professor, pois isto influencia seu cotidiano em sala de aula. Dessa forma, o professor passará a se sentir mais seguro e com maiores possibilidades de realizar um trabalho com qualidade diante de uma sala de aula heterogênea.

\subsection{UTILIZAÇÃO DE ESTRATÉGIAS PEDAGÓGICAS DIFERENCIADAS E FORMAÇÃO DE REDE NA ESCOLA}

O que observamos foi que $40 \%$ dos professores entrevistados referiram a pouca utilização de estratégias pedagógicas diferenciadas. Estes também apontaram a falta de apoio dentro da própria escola para pensar e colocar em prática tais estratégias.

Apesar disso, para um outro grupo de cerca de $60 \%$ a utilização de estratégias apareceu de forma mais consistente, como por exemplo: as possibilidades de discussão com a professora da SAAI, como sendo um apoio efetivo da coordenação pedagógica. Uma das professoras entrevistadas apontou:

Material escolar, a gente faz muita adaptação. Para criança com paralisia cerebral, por exemplo, que não consegue pegar no lápis, a gente engrossa com espuminha, põe fita crepe para facilitar, aprender cores, lateralidade, jogos, leitura, história. (P11, Entrevista 11)

Ou ainda:

A gente adapta. Por exemplo, uma história: eu contei uma história e depois eu peço para eles me contarem oralmente. Todos os alunos participam dessa fase. A gente faz a roda, e eu vou escrevendo na lousa do jeito que eles me falaram. Aí eu leio para eles, e vamos fazendo de novo. Às vezes uso objetos concretos para aqueles que têm dificuldade de compreensão.(P 6, entrevista 6)

A utilização de estratégias pedagógicas diferenciadas é sem dúvida uma vertente para equiparação de oportunidades, porém para que os professores 
possam utilizá-las é preciso que reconheçam em todos os seus alunos sujeitos capazes de aprender, favorecendo a construção de uma educação de qualidade para todos os envolvidos. De acordo com Aranha e Silva:

[...] Pensar na Educação Inclusiva como uma possibilidade de construção de uma sala de aula melhor na qual alunos e professores sintam-se motivados a aprender juntos e respeitados nas suas individualidades, parece que realmente pode vir a ser um progresso na história da educação brasileira. (ARANHA, SILVA; 2005, p.4)

A formação de rede dentro da própria escola também apareceu como um apoio fundamental. Esse apoio se refletiu, sobretudo, na parceria com ocoordenador pedagógico e com a professora de SAAI. Além disso, alguns professores colocaram o inicio das parcerias com os Cefais. Os professores apontam:

A coordenadora pedagógica fez várias coisas para ajudar a gente, inclusive buscar informações sobre a possibilidade de ter número de alunos menor na sala quando tem uma criança com deficiência. Apesar disso, a nossa escola tem muita demanda [...] A gente tenta manter um limite de até 35 alunos na sala, mas existe um acordo interno nessa escola [com o qual] os professores concordaram; então, quem tem alunos de projeto (de inclusão) fica com menos alunos na sala, e quem não tem fica com um número maior (P8, Entrevista 8)

Através dessas falas percebemos que apesar das dificuldades, a comunidade escolar não fica paralisada e busca alternativas que favorecem a prática em sala de aula. Alguns educadores procuram assumir o papel de educar todo e qualquer aluno e isso é fundamental como apontam Barbosa e Gomes :

[...] Enquanto os docentes não modificarem e redimensionarem sua prática profissional para ações mais igualitárias, isto é, não se posicionarem efetivamente como responsáveis pelo ato de educar também alunos com necessidades educacionais especiais, o professor terá diante de si um obstáculo e não um estímulo para aproveitar todas as oportunidades de formação permanente. (BARBOSA, GOMES; 2006 p.8)

As parcerias com os diferentes agentes tão fundamentais para um processo de inclusão de sucesso e apareceram como ferramentas fundamentais no apoio e suporte à inclusão, mas também no desenvolvimento do trabalho com todos os alunos.

\section{CONSIDERAÇÕES FINAIS}

A inclusão escolar de crianças com deficiência ainda é um processo em construção e os agentes da comunidade escolar têm pouca participação para construir uma lógica, que acolha as diferenças. De fato, em sua maioria, ainda vivenciam um papel de executores da política de Educação Inclusiva. 
De maneira geral, percebemos que para os diferentes agentes, a problematização ainda está focada na criança com necessidade educacional especial e em poucos discursos os próprios professores consideraram a possibilidade de redimensionar a sua prática pedagógica, o que é fundamental para o desenvolvimento das estratégias de ensino, que se constituíram em preocupação deste estudo. Dessa forma, acreditamos que é fundamental, que os professores possam lidar com os sentidos e imaginários que têm sobre a deficiência e as perspectivas de aprendizagem que têm para seus alunos para assim construírem um olhar voltado para as possibilidades e para a valorização das diferenças individuais dos alunos em sala de aula.

Ao mesmo tempo, reconhecemos atores e ações que valorizam e respeitam as diferenças individuais, que percebem as dificuldades, mas não se paralisam diante destas, o que os levou a realizar experiências, que buscam afirmar a capacidade de aprender de todas as crianças e seu direito a estar e participar da escola. Muitas destas experiências foram construídas a partir da formação de uma rede de apoio como, entre, por exemplo, as SAAIs, o próprio Cefai e os professores, com repercussões e desdobramentos para a criação de estratégias pedagógicas diferenciadas.

Todo esse processo envolve uma dialética de exclusão/inclusão social de diferentes atores: crianças com deficiência e professores e um significativo sofrimento cotidiano de ambas as partes.

A partir desses elementos é possível indicar a necessidade e urgência de criar e dar continuidade a iniciativas para construir processos de educação inclusiva, que considerem desde a garantia de matrículas até a qualidade do ensino e da participação desses estudantes. Ao mesmo tempo esses processos devem considerar o cenário concreto das escolas, bem como a necessidade de transformar os princípios e diretrizes gerais da política municipal em condições objetivas para favorecimento dos processos de inclusão escolar. Para tanto é fundamental o envolvimento efetivo de diferentes atores (educadores, familiares, crianças com deficiência, comunidade escolar).

Entendemos também que no cotidiano escolar é necessário aprofundar as discussões e sistematizar ações para a formação de rede de apoio a professores e crianças e é fundamental potencializar estratégias pedagógicas (gerais e específicas) a serem utilizadas com todos os alunos em sala de aula.

O número excessivo de alunos nas salas e o pouco investimento na formação de professores também receberam destaque nos discursos dos educadores. A partir disso, é forçoso reconhecer que tais aspectos dificultam o trabalho dos professores e isso se reflete em todos os seus alunos.

Nesse sentido é que podemos afirmar que muitas das mudanças apontadas como fundamentais pela política da Educação Inclusiva - como um número menor de alunos na sala de aula, a formação continuada dos professores, a utilização de 
estratégias pedagógicas diferenciadas - têm que caminhar simultaneamente com a ampliação da qualidade de ensino para todos os alunos.

Acreditamos na necessidade de aprofundar este estudo, com maior possibilidade de escuta dos professores através de encontros, de observação e participação nas situações cotidianas de ensino nas classes comuns. A ampliação das oportunidades de escuta e reflexão poderia ser geradora de uma nova postura, que possibilitaria profissionais mais amparados e confiantes diante do sofrimento que vivenciam com a falta de apoio, muitas vezes, da própria escola.

Como terapeuta ocupacional, um dos profissionais que pode compor as equipes multiprofissionais de apoio à inclusão, acredito que seria interessante desenvolver outros estudos para aprofundar os conhecimentos acerca do cotidiano das escolas, das atividades e estratégias pedagógicas propostas para todos os alunos e da dinâmica em sala de aula. Para tal aprofundamento poderiam ser utilizados diversos recursos como oficinas para confecção de materiais adaptados, que poderiam auxiliar na criação e aperfeiçoamento de estratégias pedagógicas, debates sobre filmes, vivências diversas que facilitassem o aparecimento dos sentidos e imaginários sobre deficiência, as dificuldades enfrentadas em sala de aula, e ao mesmo tempo auxiliassem os agentes da comunidade a ampliar seu repertório de atividades e ações em sua prática.

O estudo aproximou a pesquisadora do campo de conhecimento da Educação Inclusiva como parte da Educação para Todos, e consequentemente sobre os desafios colocados para a implementação da política de inclusão escolar de crianças com necessidades educacionais especiais. Também trouxe contribuições sobre o processo de exclusão/inclusão de crianças com deficiência na classe comum, assim como possibilitou o reconhecimento do sofrimento do professor nessa trajetória e a necessidade de estratégias diferenciadas e diversificadas para todos os alunos, que envolvam a comunidade escolar em busca de uma prática, que efetivamente acolha a diferença.

\section{REFERÊNCIAS}

ALMIRALL, C.B.; SORO-CAMATES, E. ; BULTÓ, C.R. Sistemas de sinais e ajudas técnicas para comunicação alternativa e escrita: princípios teóricos e aplicações. São Paulo: Santos, Livraria Editora, 2003.

ANJOS, H. P.; ANDRADE, E. P.; PEREIRA, M. R. A inclusão escolar do ponto de vista dos professores: o processo de constituição de um discurso. Revista Brasileira de Educação, v.14, n.40, p.116-129, 2009. 
ARANHA, M.S. SILVA S.C. Interação entre professora e alunos em salas de aula com proposta pedagógica de educação inclusiva. Revista Brasileira de Educação Especial, v.11, n.3, p.4, 2005.

BARBOSA, A; GOMES, C. Inclusão escolar do portador de paralisia cerebral: atitudes de professores do ensino fundamental. Revista Brasileira de Educação Especial, v.12, n.1, p.8, 2006.

BEYER, H. O. A educação inclusiva: incompletudes escolares e perspectivas de ação. Cadernos de Educação Especial. Santa Maria, n.22, p.5, 2003. Disponível em: <http:/ / www. ufsm.br/ce/revista/ceesp/2003/02/a3.htm>. Acesso em: 18 ago. 2010.

BORDENAVE, J.D; PEREIRA, A.M. Estratégias de ensino-aprendizagem.28.ed.Rio de Janeiro: Vozes, 2007.

BRACCIALLI, L.M.P.; PAIVA, P.C. Textura do recurso pedagógico e implicações em atividades de encaixe realizada por indivíduos com Paralisia Cerebral. Revista Brasileira de Educação Especial, v.15, n.2, p.1.2010.

BRASIL. Lei n9394, de 20 de dezembro de 1996 (Estabelece as diretrizes e bases da Educação Nacional). Disponível em: <http:/ / www.planalto.gov.br/ccivil-03/Leis/ 19394.> Acesso em: 22 nov.2010.

CARLINI AL. E agora: preparar a aula. In: SCARPATO, M. (Org.). Os procedimentos de ensino fazem a aula acontecer. São Paulo: Avercamp; 2004.

CHIZZOTI, A. Pesquisa em ciências humanas e sociais. São Paulo: Cortez; 2003.

FERRAZ, C.R.A; ARAUJO, M.V.; CARREIRO, L.R. Inclusão de crianças com Síndrome de Down e paralisia cerebral no ensino fundamental I:comparação dos relatos de mães e professores. Revista Brasileira de Educação Especial, v.16, n.3, 2010.

HUMMEL, E.I. A formação de professores para o uso da informática no processo de ensino e aprendizagem de alunos com necessidades educacionais especiais em classe comum. 2007. 214f. Dissertação (Mestrado em Educação) Universidade Estadual de Londrina, Londrina, 2007.

LEONARDO, N. S. T. Inclusão escolar: um estudo acerca da implantação da proposta em escolas públicas. Psicologia Escolar e Educacional, Campinas, v.12, n.2, 2008.

MANZINI, E.J. SANTOS, M.C.F. Portal de ajudas técnicas para educação: equipamento e material pedagógico para educação, capacitação e recreação da pessoa com deficiência física: recursos pedagógicos adaptados. Brasília: MEC: SEESP, 2002, fascículo 1.

MANZINI, E.J. DELIBERATO, D. Portal de ajudas técnicas: equipamentos e material pedagógico para educação, capacitação e recreação da pessoa com deficiência física: recursos para comunicação alternativa. Brasília: MEC: SEESP, 2004, v.2.

MARTINS, L.A.R. Inclusão escolar: algumas notas introdutórias. In: MARTINS, L.A.R.et.al. (Org.). Inclusão: compartilhando saberes. Petrópolis: Vozes, 2006.

MAY, T. Pesquisa social: questões, métodos e processos. Porto Alegre: Artmed, 2004.

PERRENOUD, P; THURLER, M.G. As competências para ensinar no século XXI: A formação de professores e o desafio da avaliação. Porto Alegre: Artmed, 2001.

SOLÉ L. Aprender e ensinar na educação infantil. Porto Alegre: Artmed; 1999. 
BRIANT, M. E. P.; OLIVER, F. C.

STAINBACK, A.; STAINBACK, W. Inclusão - um guia para educadores. Traduzido por Magda França Lopes. Porto Alegra: EDUC, 1999.

VITALIANO, C.R. Análise da necessidade de preparação pedagógica de professores de cursos de licenciatura para inclusão de alunos com necessidades educacionais especiais. Revista Brasileira de educação. Marília, v.13, n.3, p.399-414, 2007.

Recebido em: 27/04/2011

Reformulado em: 20/11/2011

Aprovado em: 01/02/2012 